\title{
APLICAÇÃO DA FITORREMEDIAÇÃO EM FUNÇÃO DE TIPOLOGIAS \\ DE INFRAESTRUTURA VERDE EM MICROBACIAS URBANAS \\ DA CIDADE DE SÃO PAULO
}

APPLICATION OF PHYTOREMEDIATION ACCORDING TO

GREEN INFRASTRUCTURE TYPOLOGIES IN URBAN WATERSHEDS

IN THE CITY OF SÃO PAULO

\author{
Maitê Bueno Pinheiro \\ Bacharel em Ciências Biológicas, especialista em Química Ambiental, mestranda do curso de \\ Arquitetura e Urbanismo, linha de pesquisa Paisagem e Ambiente da Faculdade de \\ Arquitetura e Urbanismo da Universidade de São Paulo (FAU-USP). \\ Email: maite.biologia@gmail.com
}

\begin{abstract}
RESUMO
Este artigo investiga a aplicação da fitorremediação em função de tipologias de Infraestrutura Verde (IV) em microbacias urbanas da cidade de São Paulo. Para esta investigação utilizou-se o reconhecimento das tipologias de Infraestrutura Verde para sua aplicação em uma microbacia densamente urbanizada da cidade, realizado no recente trabalho de Bonzi (2015). Este estudo é parte integrante de pesquisa mestrado em andamento que, em seus resultados preliminares, apresenta a tipologia biovaleta como sendo bastante indicada à tecnologia de fitorremediação. A fitorremediação é uma tecnologia emergente que utiliza os mecanismos naturais das plantas e suas interações com a microbiota associada para a degradação, contenção, imobilização e extração de poluentes orgânicos e inorgânicos, e pode ser aplicada para o tratamento da poluição das águas urbanas em função das tipologias paisagísticas de Infraestrutura Verde. A Infraestrutura Verde é uma rede de áreas paisagisticamente interconectadas que pode ser compreendida como uma ferramenta para o reconhecimento e aproveitamento de serviços ecossistêmicos no ambiente urbano. A IV tem sido considerada na literatura especializada como uma ferramenta capaz de atender às demandas das questões ambientais das cidades, especialmente no que diz respeito ao manejo quantitativo e qualitativo das águas.
\end{abstract}

Palavras-chave: Fitorremediação; Infraestrutura Verde; águas urbanas; microbacias urbanas; São Paulo. 


\begin{abstract}
This article investigates the use of phytoremediation in function of Green Infrastructure (GI) typologies in urban micro watersheds of São Paulo. For such investigation it was used the recognition of Green Infrastructure typologies for its application in a densely urbanized micro watershed of the city, performed in the recent work of Bonzi (2015). That study is part of a master degree research in progress that in its preliminary results introduces the bio-ditch typology as being well suited to the phytoremediation technology. Phytoremediation is an emerging technology that uses the natural mechanisms of plants and their interactions with the microbiota associated with the degradation, containment, immobilization and extraction of organic and inorganic pollutants. It can be applied to the treatment of urban water pollution according to the Green Infrastructure landscape typologies. The Green Infrastructure is a network of interconnected landscaped areas which can be understood as a tool for the recognition and use of ecosystem services in the urban environment. Specialized literature has been considering $\mathrm{Gl}$ the as a tool able to meet demands of cities' environmental issues, especially with regard to the quantitative and qualitative management of water.
\end{abstract}

Keywords: Phytoremediation; Green infrastructure; Urban Water; Urban Watersheds; City of São Paulo.

\title{
INTRODUÇÃO
}

Este artigo tem como propósito investigar a aplicação da fitorremediação na despoluição das águas urbanas utilizando-se tipologias da Infraestrutura Verde (IV) e realizar um estudo preliminar das possibilidades de sua aplicação nas águas da cidade de São Paulo. Tal investigação se insere na pesquisa de mestrado em andamento, intitulada "Infraestrutura Verde de manejo in situ das águas urbanas: Fitorremediação como mecanismo de seleção das espécies vegetais"1.

A fitorremediação é o nome dado à tecnologia que utiliza as plantas e as suas in-

\footnotetext{
1 Orientador Prof. Dr. Paulo Renato Mesquita Pellegrino. Faculdade de Arquitetura e Urbanismo da Universidade de São Paulo - FAU-USP. Conta com bolsa de estudos, processo: n. 2014/14998-6, Fundação de Amparo à Pesquisa do Estado de São Paulo - FAPESP.
} 
terações com a microbiota associada na remediação de ambientes contaminados (EPA, 2000; SALT; SMITH e RASKINL, 1998; SALT et al, 1995; RASKIN et al, 1994 apud PILLON-SMITS, 2005; PILON-SMITS, 2005). Esta tecnologia compreende um conjunto de mecanismos que dizem respeito aos processos naturais das plantas e às suas interações com os microorganismos da rizosfera ${ }^{2}$ para degradar, extrair, conter ou imobilizar contaminantes orgânicos e inorgânicos presentes nos solos, sedimentos, águas superficiais e águas subterrâneas (RUBY e APPLETON, 2010; PIRES et al, 2003 apud COUTINHO, 2007; EPA, 2000; SALT; SMITH e RASKINL, 1998; SALT et al, 1995; RASKIN et al, 1994 apud PILLON-SMITS, 2005).

O termo fitorremediação (phyto = planta; remediar = corrigir o mal), é relativamente recente, passou a ser empregado no ano de 1991 (EPA, 2000), na mesma década em que se tornou popular para as agências governamentais e para o setor industrial dos Estados Unidos e da Europa (PILON-SMITS, 2005). Nos Estados Unidos, os conhecimentos sobre os mecanismos envolvidos na fitorremediação foram adquiridos através das experiências com os problemas ambientais relativos às atividades de agricultura, silvicultura e horticultura (EPA, 2000).

A fitorremediação é eficiente para uma gama de poluentes orgânicos e inorgânicos como metais, metalóides, hidrocarbonetos do petróleo, compostos orgânicos voláteis (VOCs), pestiscidas, herbicidas, nutrientes, radionuclídeos, organoclorados, solventes clorados, explosivos, fenóis e nutrientes inorgânicos (MORENO et al, 1998; MORENO e SÍGOLO, 2007; PILON-SMITS, 2005; EPA, 2000; DUSHENKOV, et al, 1995).

Atualmente, a fitorremediação tem sido identificada como o método mais rentável, não invasivo e publicamente aceito no tratamento de ambientes contaminados (RUBY; APPLETON, 2010). Seus mecanismos naturais de remediação são movidos pela energia solar, constituindo uma tecnologia atraente do ponto de vista econômico, se comparada a tecnologias convencionais de remediação (GERHARDT et al, 2009). Confere caráter estético positivo à paisagem e tem potencial de devolver ao solo materiais orgânicos, nutrientes e oxigênio através das plantas e dos processos metabólicos microbianos (PILON-SMITS, 2005; ALORKA; GARBISU, 2001). Além disso, a

\footnotetext{
${ }^{2}$ A rizosfera compreende a área de aproximadamente $1 \mathrm{~mm}$ ao redor da raíz e encontra-se sobre influência da planta, que libera pelas raízes uma variedade de compostos orgânicos derivados da fotossíntese, chamados fotossintatos. Estes fotossintatos servem de recursos para fungos heterotróficos e bactérias e são o fator substancial para a área de degradação ao redor das raízes (PILON-SMITS, 2005).
} 
introdução da cobertura vegetal promove: estabilização do solo atenuando processos erosivos (GERHARDT et al, 2009), recarga dos aquíferos e lençóis freáticos, proteção das nascentes, cursos d'águas e proteção para biodversidade (SMA, 2009).

AAgência de Proteção Ambiental dos Estados Unidos (U. S. Environmental Protection Agency - EPA) inclui a fitorremediação no grupo de melhores práticas de gestão das águas da chuva (Best Management Practices - BMPs). As BMPs incorporam o conceito de desenvolvimento de baixo impacto (Low Impact Development - LID), uma abordagem ecológica de gestão das águas pluviais, favorecida pelo uso de "engenharias suaves" (soft engineering) e de uma rede de vegetação que, atua tanto no controle das vazões como da poluição difusa. O objetivo do LID é reduzir os impactos da urbanização sobre os recursos hídricos, buscando devolver as condições pré-urbanas da bacia hidrográfica, através da rede de paisagens naturalizadas, planejadas desde o lote residencial para toda a bacia (UACDC, 2010). Tais estratégias, BMPs e LID, são empregadas com a utilização de um sistema de Infraestrutura Verde (IV).

\section{Infraestrutura Verde (IV)}

A Infraestrutura Verde (IV) é uma rede interconectada de áreas naturais e outros espaços abertos, paisagisticamente tratados, capazes de desempenhar as funções ecológicas e hidrológicas dos ecossistemas no meio urbano. Do ponto de vista do planejamento regional, a IV incorpora as áreas de conservação públicas e privadas, áreas trabalhadas com valores de conservação e outros espaços abertos protegidos que atuam na conservação dos valores dos ecossistemas naturais e suas funções como mananciais (CORMIER; PELLEGRINO, 2008).

No campo do urbanismo e da arquitetura da paisagem, uma série de outros conceitos vêm sendo explorados para atender às questões urbanas - Estrutura Ecológica, Novo Urbanismo (New Urbanism), Urbanismo Paisagístico (Landscape Urbanism), Planejamento Ambiental, Urbanismo Biomimético e Urbanismo Biofílico. Com Bonzi, (2015 p. 42) a IV "emerge como ponto em comum a todas essas escolas, sobretudo no que diz respeitos a suas tipologias e enquanto proposta de configuração espacial - rede de áreas interconectadas."

A IV compreende uma diversidade de tipologias paisagísticas, como jardins de chuva, biovaletas, tetos verdes, wetlands construídos e canteiros pluviais que atuam no 
manejo das água, quantitativamente e qualitativamente, em diversas escalas. Essas tipologias incorporam funções infraestruturais aos espaços abertos do tecido urbano, por combinarem tecnologias de alto desempenho (CORMIER; PELLEGRINO, 2008), que promovem serviços relacionados à drenagem, ao mesmo tempo em que conferem respostas aos probemas de mobilidade, acesso, conforto ambiental, despoluição das águas e do ar, fomento à biodiversidade, lazer e imagem local (BONZI, 2015).

A IV incorpora a visão de que a conservação da natureza não precisa se opor ao desenvolvimento, ela fornece uma organização espacial que proporciona, simultaneamente, lugares para o desenvolvimento das atividades sociais e para o fornecimento dos benefícios da natureza (BENEDICT; McMAHON, 2006).

De acordo com Cormier e Pellegrino (2008), a IV pode ser compreendida como uma ferramenta para o reconhecimento e aproveitamento de serviços ecossistêmicos no ambiente urbano. Os serviços ecossistêmicos ${ }^{3}$ são serviços prestados pelos ecossistemas que conferem benefícios à qualidade de vida humana. São divididos em quatro categorias: a. Serviços de suporte, como formação do solo, ciclagem de nutrientes, fotossíntese (SANTOS, 2014); b. Serviços de regulação, como regulação do clima, purificação da água e do ar, regulação de enfermidades, entre outros; c. Serviços de provisão, de alimentos, matéria prima, combustíveis etc.; d. Serviços culturais, recreativos, estéticos, espirituais e religiosos, turísticos, entre outros (AEM, 2005 apud ROSA, 2014).

$\mathrm{Na}$ IV a água é o elemento de conectividade, facilitador da biodiversidade e provedor do suporte aos diversos processos e serviços ecossistêmicos. A hidrologia tem papel principal entre os processos envolvidos, é indicadora das condições urbanas e fator de influência sobre aspectos culturais e biofísicos (MOURA, 2013).

A IV é uma estratégia de interesse para aplicação da fitorremediação no tratamento da poluição das águas urbanas. E de acordo com Bonzi (2015) os atributos da IV privilegiam sua aplicação em bacias hidrográficas localizadas em áreas densamente urbanizadas, como na cidade de São Paulo.

${ }^{3}$ O conceito de serviço ecossitêmico se consolidou em 2005 com a Avaliação Ecológica do Milênio (AEM), e suas bases teóricas se encontram na busca pelo entendimento das relações entre os ecossistemas e a qualidade da vida humana. O conceito engloba os termos serviços da natureza, capital natural e serviços ambientais. Os conflitos existentes em sua classificação são discutidos nos trabaIhos de Rosa (2014) e Santos (2014). 
Nesse sentido, o presente estudo se justifica ao visar contribuir com a ampliação dos conhecimentos sobre a fitorremediação como meio para a recuperação da qualidade das águas urbanas e sua aplicação em função das tipologias da Infraestrutura Verde em microbacias da cidade de São Paulo.

\section{A poluição das águas urbanas}

Na natureza, a vegetação e a água são indissociáveis. A vegetação promove a manutenção do ciclo hidrológico e está diretamente relacionada à permeabilidade dos solos, sendo um fator determinante para a regularidade da vazão dos rios. Especialmente a vegetação que ladeia os cursos d'água, denominada mata ciliar, estabiliza as margens, diminui o risco de erosão e assoreamento dos cursos hídricos, minimiza as contaminações químicas e biológicas e são mitigadoras de perdas de água por evaporação (SMA, 2009).

No ambiente urbano, as paisagens naturais foram alteradas ao longo do tempo pelo processo de urbanização, que gerou uma série de impactos ambientais negativos e perda da provisão dos serviços ecossistêmicos.

Segundo Bonzi (2015), parte dos problemas urbanos são consequências de um processo que se deu indiferente à base biofísica da paisagem, fundamental para o desenvolvimento da cidade.

Na cidade de São Paulo, a poluição das águas urbanas, é resultado de um conjunto de efeitos, bastante conhecidos, provocados pelo processo de urbanização caracterizado por crescimento acelerado e irregular, poluição da atmosféra, intensa impermeabilização dos solos, processos erosivos, alterações no microclima, ocupação das áreas de várzeas por avenidas de fundo de vale e ocupações irregulares (LEITE, 2008), além de um mosaico de áreas contaminadas (MORINAGA, 2013).

A atual contaminação das águas urbanas não somente está associada ao processo histórico, acima mencionado, mas também a fatores como:

a. Deficiências atuais no sistema de tratamento, coleta e transporte de esgoto e ligações clandestinas de esgoto às tubulações da infraestrutura de drenagem de águas pluviais; 
b. Contaminação dos solos, que posteriormente leva à contaminação das águas subterrâneas e superficiais, sendo comum em áreas urbanas a contaminação por atividade de postos de combustível (PINHEIRO, 2012);

c. A chuva ácida, ocasionada pela poluição atmosférica;

d. Supressão de vegetação e ocupação das planícies aluviais e várzeas;

e. Aumento de áreas impermeáveis, o que incrementa a carga de poluição difusa ${ }^{4}$ carregada pelo esoamento das águas pluviais, sendo esta a principal fonte de poluição das bacias urbanas atualmente ${ }^{5}$;

f. Fertilizantes de áreas agrícolas e ajardinadas que contribuem com a introdução de nitratos e fostatos nos sistemas locais de drenagem, provocando eutrofização dos corpos hídricos à jusante (DANIELS, 2003 apud PLATT, 2006).

\section{Mecanismos da fitorremediação e aplicações}

A fitorremediação é classificada de acordo com o destino dos contaminantes -degradação, extração, contenção ou imobilização e volatilização - e com base nos mecanismos vegetais envolvidos, quais sejam: extração de contaminantes do solo ou água subterrânea; concentração de contaminantes no tecido da planta; degradação dos contaminantes a partir de processos bióticos ou abióticos; volatilização ou transpiração de compostos voláteis das plantas para atmosfera; imobilização dos contaminantes na rizosfera; controle fitohidráulico dos contaminantes na água subterrânea (controle da pluma de contaminação); controle do escoamento; erosão; e infiltração pela cobertura vegetal (EPA, 2000).

\footnotetext{
${ }^{3}$ Poluição proveniente de atividades que depositam poluentes de forma esparsa sobre a área de contribuição da bacia hidrográfica. Ela é formada por resíduos de origem bastante diversificada, como os provocados pelo desgaste do asfalto pelos veículos, o lixo acumulado nas ruas e calçadas, as decomposições orgânicas, as sobras de materiais das atividades de construção, os restos de combustível, óleos e graxas deixados por veículos, poluentes do ar, etc. (AESABESP, 2008).

${ }^{4} \mathrm{O}$ escoamento pluivial carrega expressivas cargas de poluição difusa, principalmente no primeiro fluxo de escoamento (first flush), onde a contaminação é muitas vezes maior do que a normalmente encontrada nos esgotos (MOURA, 2013).
} 
Os mecanismos da fitorremediação são divididos em dois tipos, mecanismos de ação direta e ação indireta. Fitoextração, rizofiltração, fitodegradação, fitovolatilização e controle fitohidráulico são mecanismos de ação direta. Já fitoestabilização, rizodegradação, sistemas de cobertura vegetal e corredores ripários, são mecanismos de ação indireta (EPA, 2000). Estes mecanismos podem agir em conjunto ou isoladamente nos diferentes substratos - solos, sedimentos, lamas, águas superficiais e subterrâneas - atingindo uma variedade de poluentes orgânicos e inorgânicos e envolvem grande diversidade de espécies de plantas macrófitas (plantas aquáticas) e terrestres.

A seguir, apresenta-se um desenho esquemático e breve descrição de alguns dos mecanismos da fitorremediação.

\section{MECANISMOS DA FITORREMEDIAÇÃO}

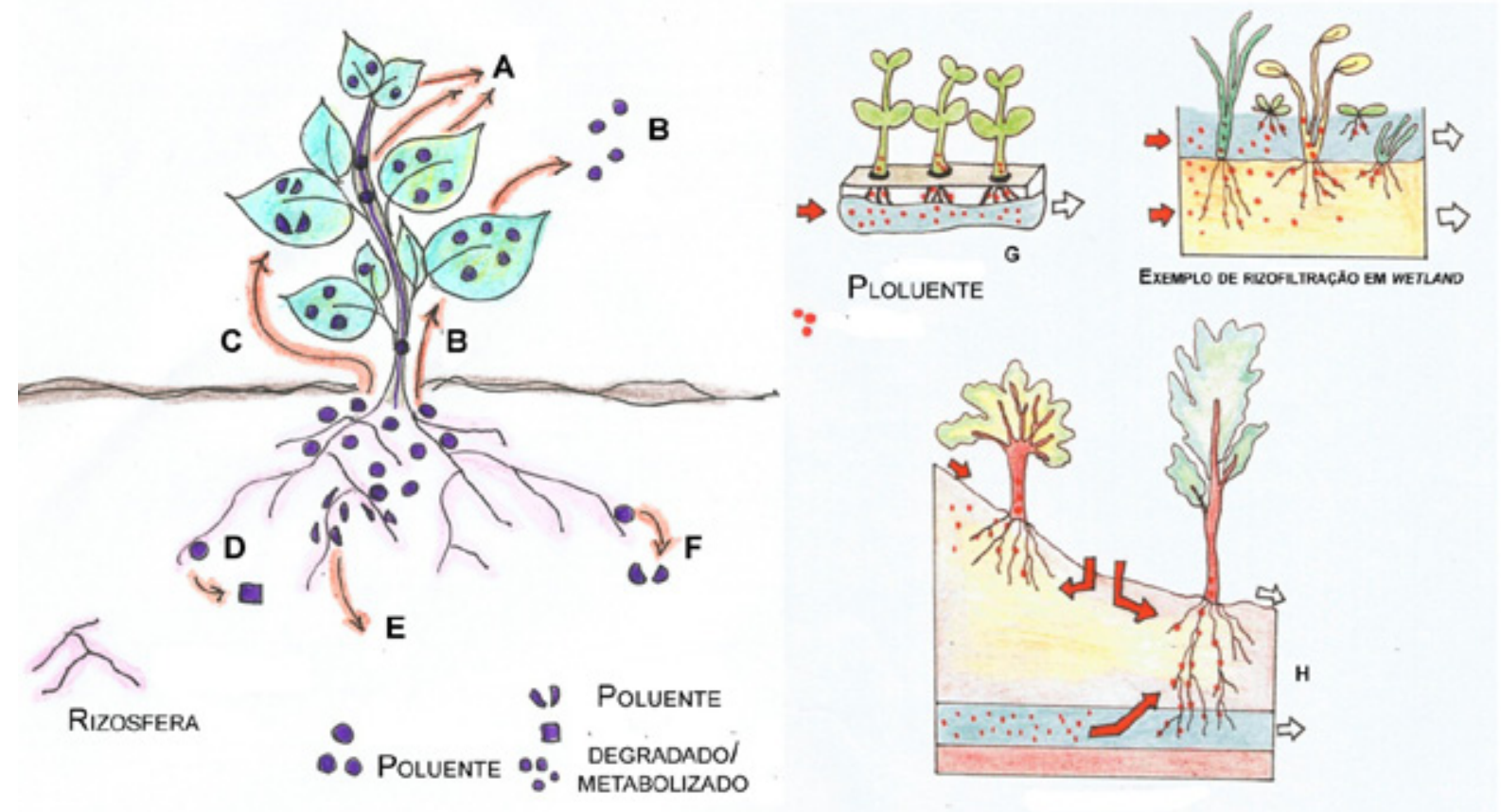

Figura 1 - Desenho esquemático dos mecanismos da fitorremediação.

Fonte: Adaptação de Pilon-Smits (2005).

\section{Mecanismos de ação direta:}

A - Fitoextração: Absorção direta de metais, metalóides e alguns radionuclídeos pelas raízes e translocação para os tecidos aéreos da planta, a partir de espécies de plantas denominadas hiperacumuladoras (MORENO; SíGOLO, 2007; EPA, 1999). A remoção dos metais retidos nos tecidos das plantas é feita através de ciclos de colheita. Os vegetais depois de colhidos podem ser incinerados ou reciclados. Ciclos de plantio e colheita podem ser feitos sucessivamente de 
acordo com o grau da contaminação. No caso de incineração dos vegetais, as cinzas geradas devem ser descartas em um aterro específico para resíduos perigosos (EPA, 1999). Inicialmente, a fitoextração foi utilizada para o tratamento de solos e sedimentos contaminados por metais e metalóides, mas pode ser aplicada para o tratamento de águas com níveis baixos de contaminação (EPA, 2000).

B - Fitovolatilização: Absorção do contaminante pelas raízes e sua posterior liberação pelas folhas ou raízes na forma volátil para a atmosfera, podendo ou não sofrer modificações nas suas propriedades químicas (MORENO; SíGOLO, 2007). Quando os contaminantes absorvidos são convertidos em formas menos tóxicas, uma vez na atmosfera podem sofrer processos naturais como a fotodegradação. A fitovolatilização oferece a possibilidade de remoção completa do contaminante, mas é necessário considerar os níveis e as propriedades tóxicas dos gases/vapores liberados, pois podem conferir risco ao ambiente e às pessoas. (PILON-SMITS, 2005). Este mecanismo pode ser aplicado no tratamento de águas subterrâneas, solos, sedimentos e lamas, porém os solos devem oferecer as condições adequadas em relação à quantidade de água para que os contaminantes possam ser absorvidos (EPA, 2000).

C - Fitodegradação: Degradação e/ou transformação de compostos no interior da planta. Este mecanismo ocorre após a absorção do contaminante através de processos metabólicos, ou na rizosfera por meio da ação de complexos enzimáticos liberados pelas raízes. Neste mecanismo não é considerada a ação dos microorganismos presentes na rizosfera, as transformações no interior da planta são a principal via de ação (EPA, 2000). As transformações ocorridas dependem das propriedades dos compostos envolvidos e da absorção do contaminante pela planta, influenciada pelas propriedades hidrofóbicas de solubilidade e polaridade dos contaminantes (KAMATH et al. 2005). A fitodegradação pode ser aplicada no tratamento de solos, sedimentos, lamas, águas subterrâneas e águas superficiais (EPA, 2000).

F - Rizofiltração in situ e ex situ: Absorção ou precipitação do contaminante presente na água, ou em solução na rizosfera, pelas raízes das plantas através de processos bióticos e abióticos. A absosrção, concentração ou transporte dos contaminantes pelas plantas dependerá do contaminante envolvido. Os metais, por exemplo, podem ser preciptados através da ação de exudatos no interior da planta e removidos na colheita (EPA, 2000). Pode ser aplicada in situ no tratamento de corpos hídricos, através de wetlands construídos, plataformas fluantes (floating rafts), ilhas e arquipélogos flutuantes. Estas formas de aplicação também podem ser usadas no tratamento das águas das chuvas com a construção de wetlands e lagoas pluvais e também para o tratamento de efluentes domésticos e industriais. A aplicação da rizofiltração pode ser feita ex situ, conduzindo o fluxo para um local de tratamento.

G - Controle fitohidráulico: Age na contenção de plumas de contaminação por meio dos mecanismos de infiltração e bombeamento (sponge pump). A configuração de um sistema raiz-planta permite a realização das funções de evapotranspiração e de retenção de água de modo equilibrado. A vegetação bombeia a água do solo e a libera para a atmosfera através da transpiração (MORENO; SíGOLO, 2007). As raízes das árvores também agem formando uma barreira eficaz impedindo a migração horizontal da pluma de contaminantes pelas águas subterrâneas (PILON-SMITS, 2005). 


\section{Mecanismos de ação indireta}

D - Fitoestabilização: Imobilização dos contaminantes no solo ou na rizosfera, que pode ser auxiliada pela adição de inertizantes. A precipitação do contaminante na rizosfera altera sua biodisponibilidade no meio. A ação das raízes também contrubui para evitar a migração dos contaminantes para a água subterrânea ou sua dispersão pelo solo, evita processos erosivos e promove mudanças nas propriedades químicas do solo, devido à liberação de exudatos pelas raízes. A liberação dessas substâncias pode ocasionar a alteração do pH e produção de gás carbônico proporcionando o aumento da comunidade microbiana, fixação de nitrogênio atmosférico e a mineralização de compostos orgânicos no solo (MORENO; SíGOLO, 2007).

E - Rizodegradação: Degradação de contaminantes na rizosfera a partir da interação entre as plantas e os microrganismos associados, os quais utilizam o elemento carbono dos contaminantes orgânicos como fonte de energia. As plantas liberam uma diversida de exudatos, substâncias como açúcares, aminoácidos, ácidos orgânicos, ácidos graxos, esteróis, enzimas e outros compostos que enriquecem e estimulam a atividade microbiana na rizosfera e proporcionam o aumento da taxa de degradação de compostos orgânicos. A presença das raízes no solo também pode afetar as condições do meio, como areação e umidade, criando condições favoráveis para que microorganismos nativos ajam na biodegradação dos compostos orgânicos, mesmo na ausência da liberação de exudatos. A rizodegradação é um mecanismo que requer um maior tempo de ação e uma extensa área de ocupação pelas raízes das plantas, além de aplicação de técnicas agronômicas, envolvendo o uso de fertilizantes, devido à competição por nutrientes entre plantas e microorganismos. Os mecanismos de fitodegradação e fitovolatilização podem acontecer junto com a rizodegradação e devem ser observados. A rizodegração é aplicada para contaminantes presentes nos solos (PILON-SMITS, 2005).

Além dos mecanismos demonstrados na figura anterior, a fitorremediação também possui o mecanismo denominado sistema de cobertura vegetal. O sistema de cobertura vegetal é de longo prazo auto-sustentável, aplicado em áreas contaminadas, incluindo áreas que oferecem riscos à saúde pública. A cobertura vegetal pode reduzir os riscos para um nível aceitável e, geralmente, com manutenção mínima. Existem dois tipos de cobertura vegetal, coberturas de evapotranspiração e coberturas de fitorremediação. Ambas atuam isolando o risco e impedindo a infiltração da água no solo contaminado, ao mesmo tempo em que degradam os poluentes. Os sistemas de coberturas de fitorremediação incorporam aspectos de controle fitohidráulico, fitodegradação, rizorremediação, fitovolatilização e, provavelmente, fitoextração (EPA, 2000). 


\section{Fitorremediação na despoluição das águas urbanas a partir das tipologias da Infraestrutura Verde: Estudo preliminar das possibilidades de aplicação para a cidade de São Paulo}

Para obter aplicação da fitorremediação no tratamento das águas urbanas é necessário identificar os problemas que afetam a qualidade das águas no âmbito da bacia hidrográfica e determinar os mecanismos da fitorremediação mais adequados para a realidade local, para então incorporá-los às tipologias da IV.

A presente investigação utilizou-se do estudo para a aplicação de tipologias de IV em uma microbacia hidrográfica densamente urbanizada, a microbacia do Água Preta ${ }^{6}$, realizada por Bonzi (2015).

O autor apresenta um plano com diretrizes desenvolvidas a partir do conceito de compartimentação ambiental de Schutzer (2012), que associa à compartimentação topográfica a ideia de valores de uso e de ocupação do território para a sociedade urbana e identifica no compartimento de relevo sua propensão ou fragilidade em atender às funções urbanas. A compartimentação ambiental é feita por meio da investigação detalhada dos compartimentos topográficos, não tem escala definida, depende da situação estudada e tem finalidade do uso urbano do território, portanto, particularmente ligada a áreas densamente urbanizadas.

Ao identificar os compartimentos ambientais da microbacia e os processos naturais predominates, Bonzi (2015) destacou o aproveitamento e o manejo desses processos a partir da aplicação de tipologias de IV.

\section{RESULTADOS}

Dentre as tipologias paisagísticas de IV reconhecidas por Bonzi (2015) para a microbacia do Água Preta, possuem interesse para aplicação da fitorremediação: jardim de chuva, canteiro pluvial, biovaleta, lagoa pluvial, alagado construído (wetland), teto

\footnotetext{
${ }^{6}$ Área localizada na zona Oeste da cidade de São Paulo, drenada por muitos córregos ocultos da cidade e que apresenta problemas típicos de áreas expressivamente adensadas: alta taxa de impermeabilização, ilhas de calor, erradicação da cobertura vegetal original, radical alteração hidrológica, enchentes, carência de áreas verdes e precariedade de mobilidade e de serviços públicos (BONZI, 2015).
} 
verde, córrego reabilitado e parque linear, sendo esta última tipologia, uma das mais importantes para o tratamento das águas urbanas. O parque linear pode ter função de proteger os cursos d'água e englobar todas as outras tipologias de IV, promovendo a gestão integrada, e fornecer uma série de serviços ecossistêmicos de suporte, regulação, provisão e serviços culturais.

Neste estudo preliminar, procuramos demonstrar como a fitorremediação pode ser utlizada na biovaleta para o tratamento das águas da cidade de São Paulo. A biovaleta, também conhecida como vala de biorretenção vegetada, é a tipologia que constiste em depressões lineares compostas de vegetação, solo e outros elementos filtrantes, que participam da limpeza da água pluvial, ao mesmo tempo em que promovem outras funcões que serão detalhadas no tópico a seguir (CORMIER; PELLEGRINO, 2008).

A escolha desta tipologia se baseou no fato de que a biovaleta pode compor todos os compartimentos ambientais indentificados na microbacia do Água Preta e por apresentar possibilidades de conexões com outras tipologias de IV, como jardins de chuvas e wetlands.

Os resultados obtidos organizam informações sobre a biovaleta, os compartimentos ambientais indicados para sua aplicação na microbacia do Água Preta, os mecanismos naturais envolvidos nesses compartimentos, a composição da tipologia na paisagem, os serviços ecossitêmicos providos, os mecanismos da fitorremediação com potencial de serem associados à biovaleta, os poluentes que podem ser remediados a partir destes mecanismos e algumas espécies de plantas investigadas na fitorremediação.

\section{Biovaletas ou valetas de biorretenção vegetadas}

As biovaletas são faixas lineares rebaixadas compostas por vegetação, solo e outros elementos filtrantes que realizam a despoluição da água da chuva e retardam a velocidade do escoamento superficial (BONZI, 2015; CORMIER; PELLEGRINO, 2008).

As biovaletas são semelhantes aos jardins de chuva, depressões topográficas que recebem o escoamento pluvial das áreas limítrofes; no entanto, atuam com maior força na infiltração da água, além de desempenharem funções de limpeza e evapotranspiração. No sistema de IV, as biovaletas conduzem o escoamento pluvial aos jardins de chuva, contribuindo para a despoluição da água no decorrer do trajeto, ao filtrar os 
poluentes a partir de seu substrato e vegetação (CORMIER; PELLEGRINO, 2008). A figura a seguir apresenta o desenho esquemático de uma biovaleta.

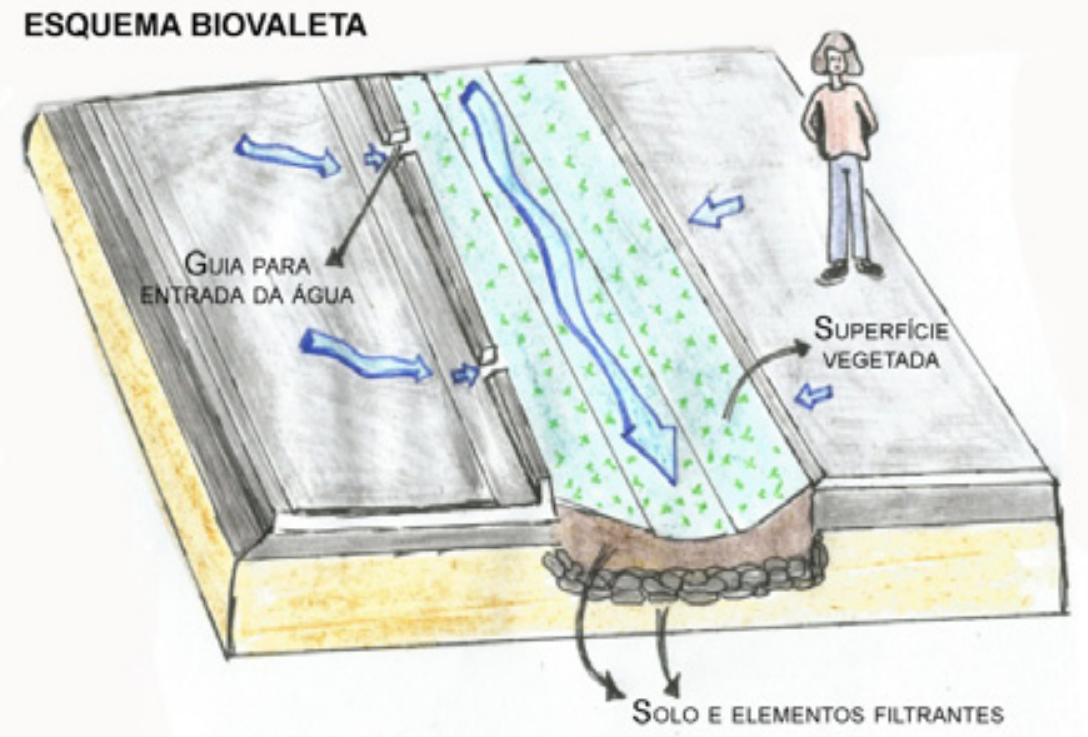

Figura 2 - Desenho esquemático da tipologia biovaleta. Fonte: Adaptado de Cormier e Pellegrino (2008).

Os processos naturais que ocorrem, passiva ou ativamente, na tipologia biovaleta são escoamento das águas, infiltração, evapotranspiração, filtragem da água e retenção da sedimentação e de materiais carreados. Os compartimentos de relevo identificados na microbacia do Água Preta que favorecem a implantação de biovaletas são as áreas tubulares livres de inundação ${ }^{7}$ (a biovaleta apresenta alto desempenho dada a facilidade de infiltração), áreas de nascentes ${ }^{8}$ e fundos de vale ${ }^{9}$ (BONZI, 2015).

${ }^{7}$ Áreas tubulares livres de inundação refere-se ao supercompartimento ambiental estruturante, formado pelos compartimentos de relevo Altas Colinas e patamares e rampas dos espigões secundários vinculados ao Espigão Central e Baixos Terraços do rio Tietê. Vasta área livre de inundações, favorável à ocupação, onde os processos de infiltração predominam sobre o escoamento superficial (BONZI, 2015).

${ }^{8}$ Áreas de nascentes correspondem às nascentes presentes em amplitude altimétrica de 750 a 795 metros (MENEGASSE-VELÁSQUEZ, 1996; SCHUTZER 2004, 2012a apud BONZI, 2015).

${ }^{9}$ Fundos de vale são o supercompartimento onde há predomínio do armazenamento de água sobre os processos de infiltração (muito limitados, devido à proximidade do lençol freático) e de escoamento superfical (praticamente limitado ao escoamento concentrado nos corpos d'água). Área com tendência a excesso de acumulação de água, aptas a abrigar parques com vegetação densa, lagos e espaços públicos institucionais de múltiplo uso (BONZI, 2015). 
As biovaletas desempenham os serviços ecossistêmicos de manejo do escoamento superficial, conservação da infraestrutura de drenagem existente, aumento da umidade do ar, remediação da poluição difusa, conectam áreas verdes e contribuem com aumento da umidade do solo adjacente (BONZI, 2015) e com a regulação do ciclo hidrológico (CORMIER; PELLEGRINO, 2008).

Esta tipologia pode ser implantada em terrenos íngremes, na forma de escadas hidráulicas, a partir de uma divisão das biovaletas em células escalonadas entre as cotas altimétricas do terreno. Nesta configuração, a água extravasa, suscetivamente, de uma célula para outra, a pressão da coluna d'água potencializa a infiltração da água no solo e a queda entre uma célula e outra dissipa a energia das águas, diminuindo a intensidade do escoamento superficial. Esta tipologia pode substituir as vias convencionais de escoamentos, compostas por pavimentos impermeabilizados. Com a implantação das biovaletas, o sistema de drenagem existente passa a atuar como um backup, recebendo o excedente do escoamento superficial nos eventos de chuvas mais intensas e/ou prolongadas e reduzindo os alagamentos nas áreas à jusante (BONZI, 2015).

Ainda no que concerne à composição paisagística, as biovaletas podem ou acompanhar o traçado das ruas, ou serem implantadas em espaços estreitos da paisagem urbana, como por exemplo, colocadas entre fileiras de estacionamentos (MOURA, 2013; CORMIER; PELLEGRINO, 2008).

\section{Mecanismos de fitorremediação associados, espécies de plantas empregadas e poluentes alcançados}

A partir do levantamento realizado, reconheceu-se três mecanismos de fitorremediação que podem ser utilizados nas biovaletas.

A fitoextração é o mecanismo que realiza a remediação da contaminação dos solos por metais e radionuclídeos. Seu emprego em biovaletas previne a contaminação das águas subterrâneas, reduz a carga de poluição que atingirá as áreas à jusante $e$ melhora a qualidade dos solos, contribuindo com o desempenho do sistema de IV. A fitoextração age na remoção de metais como Ag, As, Cd, Co, $\mathrm{Cr}, \mathrm{Cu}, \mathrm{Hg}, \mathrm{Mn}, \mathrm{Mo}, \mathrm{Ni}$, $\mathrm{Pb}$, Se e Zn (MORENO e SíGOLO, 2007; PILON-SMTS, 2005; EPA, 2000) e radionuclídeos $90 \mathrm{Sr}, 137 \mathrm{Cs}, 239 \mathrm{Pu}, 238 \mathrm{U}, 234 \mathrm{U}$ (EPA, 2000). As espécies de plantas que desempenham este mecanismo são conhecidas como plantas hiperacumuladoras e 
mais de 400 delas são reconhecidas atualmente (SZCYGLOWSKA et al, 2011; MORENO et al, 2005). As espécies da família Brassicaceae, genêro Brassica e Thlaspi, são bastante estudadas a respeito do potencial de fitoextração, especialmente a espécie Brassica juncea, popularmente conhecida como mostarda marrom (SZCYGLOWSKA et al, 2011; KUMAR et al, 1995 apud EPA, 2000; MORENO et al, 2005; EPA, 2000), entre outros gêneros e famílias.

Na Lista de Espécies da Flora do Brasil do Instituto de Pesquisa Jardim Botânico do Rio de Janeiro (JBRJ, 2013) a Brassica juncea (L.) Czern, é considerada uma espécie naturalizada brasileira, não endêmica. É uma erva de substrato terrícola, de ocorrência nas regiões Centro-Oeste (Distrito Federal e Mato Grosso), Sudeste (São Paulo) e Sul (Paraná), no domínio fitogeográfico da Mata Atlântica, reconhecida como vegetacao de Área Antrópica.

O mecanismo de fitodegradação em biovaletas age sobre a poluição difusa carregada pelo escoamento pluvial, assim como sobre os poluentes presentes no solo, previnindo a contaminação dos lençóis freáticos e das áreas à jusante. As plantas que desempenham este mecanismo atuam na degradação de compostos orgânicos, solventes clorados, herbicidas, inseticidas, explosivos (como trinitotolueno - TNT), fenóis e nutrientes orgânicos (EPA, 2000). A literatura consultada inclui a espécie de macrófita Myriophylllum aquaticum (EPA, 2000), algumas espécies arbóreas de choupos híbridos (BURKEN; SCHNOOR, 1997 apud EPA, 2000), as espécies Salix nigra e as do gênero Betula (CONGER; PORTIER, 1997 apud EPA, 2000).

Buscou-se na Lista de Espécies da Flora do Brasil (JBRJ, 2013) a corrência das espécies acima citadas, e o único gênero de ocorrência na flora brasileira é o Salix L., pertencente à família Salicaceae, espécie arbórea de origem nativa, não endêmica do Brasil. Distribui-se geograficamente nas regiões Norte (Acre, Amazonas e Pará), Sudeste (Minas Gerais e São Paulo) e Sul (Paraná, Rio Grande do Sul e Santa Catarina), nos domínios fitogeográficos da Amazônia, Mata Atlântica e Pampa.

A rizodegradação aplicada às biovaletas participa da remoção dos poluentes orgânicos retidos pelas plantas durante o escoamento da água da chuva, realizando, posteriormente, a degradação desses compostos no solo. Este mecanismo tem potencial de tratar compostos orgânicos hidrofóbicos (compostos não absorvidos pelas plantas), como as bifelinas policloradas (PCBs), os hidrocarbonetos policíclicos aromáticos (HPAs) e outros hidrocarbonetos do petróleo (PILON-SMITS, 2005), sendo estes, poluentes co- 
muns em áreas urbanas devido ao trânsito de veículos. As plantas com sistema de raízes denso e que apresentam maior tolerância aos contaminantes (PILON-SMITS, 2005) são as mais adequadas. As espécies encontradas na literatura incluem gramíneas e ervas da Família Poaceae como: Agropyron smithii, Andropogon gerardi, Bouteloua curtipendula, Bouteloua gracilis, Chloris gayana, Cynodon dactylon L., Panicum virgatum, Schizachyrium scoparius, Sorghastrum nutans, Elymus canadensis, Lolium perenne L., Medicago sativa L., Festuca arundinacea; e também a espécie da Família Apiaceae, Daucus carota, nome popular cenoura (FRICK et al. 1999).

Ambas as famílias Poaceae e Apiaceae são nativas do Brasil, e entre as espécies citadas constam na Lista de Espécies da Flora do Brasil (JBRJ, 2013):

- Panicum virgatum L., erva terrícola, cultivada originalmente no Brasil, com distribuição geográfica nas regiões Norte (Pará), Nordeste (Bahia) e Sudeste (São Paulo). Domínios fitogeográficos da Amazônia, Cerrado e Caatinga, vegetação de Área Antrópica;

- Lolium perenne L., erva terrícola, naturalizada brasileira, encontrada na região Sul (Rio Grande do Sul e Santa Catarina). Domínio fitogeográfico da Mata Atlântica, vegetação de Área Antrópica;

- Festuca arundinacea, erva terrícola, nativa do Brasil, endêmica, encontrada na região Sul (Rio Grande do Sul e Santa Catarina). Domínio fitogeográfico da Mata Atlântica, vegetação de Área Antrópica;

- Schizachyrium scoparius, Sorghastrum nutans, são espécies de gêneros nativos do Brasil, porém não são encontradas na flora brasileira;

- Daucus carota L., erva terrícola, origem no Brasil por cultivo, não endêmica, encontrada nas regiões Sudeste (São Paulo) e Sul (Rio Grande do Sul e Santa Catarina). Domínio fitogeográfico da Mata Atlântica, vegetação de Área Antrópica.

As informações coletas e organizadas neste estudo permitem avaliar a biovaleta como uma tipologia de IV de relevante interesse para a fitorremediação. A fitorremediação pode atuar, pelo menos, a partir dos três mecanismos abordados, promovendo o tratamento da poluição difusa, característica das águas das chuvas de microbacias densamente urbanizadas da cidade de São Paulo - como no estudo de caso da microbacia 
do Água Preta - ao mesmo tempo em que provê uma gama de serviços ecossistêmicos de interesse para a população local.

\section{CONSIDERAÇÕES FINAIS}

Para agir sobre o problema da poluição das águas da cidade São Paulo é fundamental uma visão integrada das questões do âmbito do uso e ocupação do solo e das infraestruturas urbanas, preconizada pelo estudo da bacia hidrográfica.

A Infraestrutura Verde tem sido demonstrada como uma ferramenta capaz de atender às demandas ambientais urbanas e de fornecer benefícios dos serviços ecossistêmicos às populações. Especialmente no que diz respeito ao manejo quantitativo e qualitativo das águas, suas tipologias paisagísticas apresentam características que permitem associá-las às tecnologias de alto desempenho, como a fitorremediação.

A fitorremediação é uma tecnologia emergente com potencial de tratar a poluição das águas urbanas. Sua aplicação em função das tipologias de IV permite que o tratamento da poluição aconteça de forma integrada, acolhendo toda a bacia hidrográfica. Além disso, seu uso contribui para melhoria da qualidade dos solos.

Diversos estudos sobre sistemas de IV estão sendo publicados e, visando sua aplicação na cidade de São Paulo, destaca-se a contribuição do trabalho de Bonzi (2015), que apresentou um plano com diretrizes para aplicação em uma microbacia densamente urbanizada na zona Oeste da cidade, a microbacia do Água Preta.

Este autor trouxe à luz a importância da identificação dos compartimentos ambientais da bacia hidrográfica para a seleção adequada das tipologias paisagístcas de IV em áreas densamente urbanizadas.

Assim, favoreceu o reconhecimento dos mecanismos de fitorremediação a partir do entendimento dos processos naturais envolvidos nos compartimentos e, portanto, o levantamento de espécies de plantas que podem realizar o tratamento da poluição das águas urbanas.

As espécies de plantas apresentadas neste artigo foram encontradas em bibliografias internacionais e estão sendo melhor investigadas para a aplicação na realidade da cidade de São Paulo. 
Os resultados ora apresentados indicam a importância do aprofundamento dos estudos sobre a associação da fitorremediação às tipologias de IV para o tratamento da poluição das águas, especialmente a poluição de caráter difuso, e do reconhecimento das espécies de plantas que desempenham mecanismos de fitorremediação e melhor possam se adequar à cidade de São Paulo.

\section{BIBLIOGRAFIA}

AESABESP - ASSOCIAÇÃO DOS ENGENHEIROS DA SABESP. Poluição por carga difusa: o impacto da poluição difusa nos centros urbanos. Revista Saneas. Ano IX, jul/ ago/set, 2008, n. 30, p. 14-25. Disponível em: <http://www.aesabesp.org.br/arquivos/ saneas/saneas30.pdf>. Acesso em: 20 de maio de 2014.

ALKORTA, I; GARBISU, C. Phytoremediation of organic contaminants in soils. Bioresource Technology, v. 79, p. 273-276, 2001.

ANTUNES, R. P. Análise do potencial de uso das macrófitas aquáticas do sistema de áreas alagadas construídas da ETE da Comunidade de Serviços Emaús (Ubatuba, SP) como adubo orgânico. São Carlos, 2009.

BIOMATRIX WATER. River Restoration. 2012. Disponível em: <http://www.biomatrixwater.com/river-restoration/>. Acesso em: 28 de maio de 2014.

BONZI, R. S. Andar sobre Água Preta: a aplicação da Infraestrutura verde em áreas densamente urbanizadas. São Paulo, 2015. 159 p.

CORMIER, N. S; PELLEGRINO, P. R. M. Infra-estrutura verde: uma estratégia paisagística para a água urbana. Revista Paisagem e Ambiente. São Paulo: FAUUSP, 2008. n 25.

COUTINHO, H. D; BARBOSA, A. R. Fitorremediação: Considerações Gerais e Características de Utilização. Silva Lusitana, Lisboa, 2007. V. 15, n. 1, p. 103- 117.

DEPARTMENT WATER AFFAIRS - DWA. Wetland and Shoreline Rehabilitation. Republic of South Africa, 2014. Disponivel em: <http://www.harties.org.za/wetshore. aspx>. Acesso em: 01 de junho de 2014. 
EPA - U. S, ENVIRONMENTAL PROTECTION AGENCY. Introduction to Phytoremediation. National Risk Management Research Laboratory Office of Research and Development, Cincinnati, Ohio, fev. 2000.

.Considerations in the Design of Treatment Best Management Practices (BMPs) to Improve Water Quality. National Risk Management Research Laboratory Office of Research and Development, set. 2002.

Case Studies Analyzing the Economic Benefits of Low Impact Development and Green Infrastructure Programs. U.S. Environmental Protection Agency Office of Wetlands, Oceans and Watersheds Nonpoint Source Control Branch. Washington, DC, ago. 2013.

FRICK, C. M; FARRELL, R. EK GERMIDA, J. J. Assessment of Phytoremediation as an In-Situ Technique for Cleaning Oil-Contaminated Sites. Department of Soil Science University of Saskatchewan Saskatoon. Saskatchewan, 1999.

GERHARDT, K. E; BETHAN, R. H. Phytoremediation and rhizoremediation of organic soil contaminants: Potential and challenges. Plant Science. 2009. V. 176, p. 20-30.

JARDIM BOTÂNICO DO RIO DE JANEIRO. Lista de Espécies da Flora do Brasil. Instituto de Pesquisa Jardim Botânico do Rio de Janeiro, 2013. Disponível em: <http:// floradobrasil.jbrj.gov.br/jabot/listaBrasil/PrincipalUC/PrincipalUC.do;jsessionid=357BF 3EFB7181AEF84B1B9638B60D041>. Acesso em: 20 de maio de 2015.

KAMATH, R.; RENTZ, J. A.; SCHNOOR, J. L.; ALVAREZ, P. J. J. Fitorremediação de solos contaminados por hidrocarbonetos: princípios e aplicações. In: MOERI, E; RODRIGUES, D; NIETERS, A. (Editores). Áreas contaminadas: remediação e revitalização. São Paulo: Signus Editora, 2005. p. 27-57.

LEITE, J. R. A ecologia da paisagem no planejamento ecológico de bacias hidrográficas urbanas. São Paulo, 2008.

MERKL, N; SHULTZE-KRAFT, R; INFANTE, C. Phytoremediation in the tropics - influence of heavy crude oil root morphological characteristics of graminoids. Environmental Pollution. Fev. 2005. V. 138, p. 86-91. 
MORENO, F. N. Avaliação experimental do potencial do chorão (Salix babylonica - Linnaeus) na fitorremediação de aquíferos contaminados por nitratos, etanos e benzeno. Florianópolis, 1998.

MORENO, F. N; ANDERSON, C.W.N; STEWART, R. B; ROBINSON, B. H. Mercury volatilisation and phytoextraction from base-metal mine tailings. Environmental Pollution, 2005, V. 136 p. 341-352.

MORENO, F. N; SÍGOLO, J. B. Fitoestabilização controlada: proposta de processo de revitalização para passivos de areias de fundição. In: MOERI, E; RODRIGUES, D; NIETERS, A. (Editores). Áreas contaminadas: remediação e revitalização. São Paulo: Signus Editora, 2007. V. 3, p. 81-99.

MORINAGA, C. M. Recuperação de áreas contaminadas: Um novo desafio para projetos paisagísticos. São Paulo, 2007.

MOURA, N. C. B. de. Biorretenção: tecnologia ambiental urbana para manejo das águas da chuva. São Paulo, 2013.

PILON-SMITS, E. Phytoremediation. Annual Review of Plant Biology. Jan. 2005. V. 56, p. 15-59.

PINHEIRO, M. B. Fitorremediação de solos contaminados por hidrocarbonetos do petróleo. São Paulo, 2012. 50 p.

PLATT, R. H. Urban Watershed management sustainability, onde stream at a time. Environment. Heldref Publications. May, 2006 v. 48, n. 4, p. 26-42.

ROSA, J. C. S. Avaliação de impactos ambientais de um projeto de mineração: Um teste metodológico baseado em serviços ecossistêmicos. São Paulo, 2014.

RUBY, M; APPLETON, B. Using landscape plants for phytoremediation. Low Impact Development 2010: Redefining Water in the City. ASCE, 2010.

SALATI, E. Controle de qualidade de água através de wetalands construídos. Rio de Janeiro, s/d. 
SALT, D. M; BLAYLOOCK, M; KUMAR, P. B. A. N; DUSCHENKOV, V; ENSLEY, B.D; CHET, I. RASKIN, I. Phytoremediation: A Novel Strategy for the Removal of Toxic Metals from the Environment Using Plants. Nature Biotechnology, 1995. V. 13, p. 468-474.

SANTOS, R. F. O contexto histórico da definição conceitual de Serviços Ecossistêmicos. Fapesp, São Paulo, 2014. Disponível em: <http://www.fapesp.br/ eventos/2014/02/biota/Rozely_Ferreira.pdf>. Acesso em: 15 de maio de 2015.

SMA. Cadernos da Mata Ciliar. Secretaria do Estado do Meio Ambiente, Coodenadoria da Biodiversidade e Recursos Naturais, N 1 (2009) - São Paulo : SMA, 2009.

SZCYGLOWSKA, M; PIEKARSKA, A; KONIECZKA, P; NAMIESNIK, J. Use of Brassica Plants in the Phytoremediation and Biofumigation Processes. International Journal of Molecular Sciences, 2011. Disponível em: <http://www. mdpi.com/1422-0067/12/11/7760> . Acesso em: 20 de maio de 2015. 